\title{
One-year outcomes after minimally invasive sacroiliac joint fusion with a series of triangular implants: a multicenter, patient-level analysis
}

This article was published in the following Dove Press journal:

Medical Devices: Evidence and Research

28 August 2014

Number of times this article has been viewed

\author{
Donald Sachs' \\ Robyn Capobianco ${ }^{2}$ \\ Daniel Cher ${ }^{2}$ \\ Timothy Holt ${ }^{3}$ \\ Mukund Gundanna ${ }^{4}$ \\ Timothy Graven ${ }^{5}$ \\ A Nick Shamie ${ }^{6}$ \\ John Cummings Jr ${ }^{7}$ \\ 'Center for Spinal Stenosis and \\ Neurologic Care, Lakeland, FL, \\ ${ }^{2} \mathrm{SI}-\mathrm{BONE}$, Inc., San Jose, CA, \\ ${ }^{3}$ Montgomery Spine Center, \\ Montgomery, AL, ${ }^{4}$ Brazos Spine, \\ College Station, TX, ${ }^{5} \mathrm{SSM}$ \\ Orthopedics, Wentzville, MO, ${ }^{\circ} \mathrm{UCLA}$ \\ Spine Center, Santa Monica, CA, \\ ${ }^{7}$ Community Neurosurgical Care, \\ Indianapolis, IN, USA
}

Background: Sacroiliac joint (SI) pain is an often-overlooked cause of lower-back pain, due in part to a lack of specific findings on radiographs and a symptom profile similar to other back-related disorders. A minimally invasive surgical (MIS) approach to SI joint fusion using a series of triangular, titanium plasma spray-coated implants has shown favorable outcomes in patients with SI joint pain refractory to conservative care. The aim of this study was to provide a multicenter experience of MIS SI joint fusion using a patient-level analysis.

Patients and methods: We report a patient-level analysis from 144 patients with a mean of 16 months postoperative follow-up. Demographic information, perioperative measures, complications, and clinical outcomes using a visual analog scale for pain were collected prospectively. Random-effects regression models were used to account for intersite variability.

Results: The mean age was 58 years, $71 \%$ of patients were female, and $62 \%$ had a history of lumbar spinal fusion. Mean ( $95 \%$ confidence interval [CI]) operative time was 73 minutes (25.4-118), blood loss was minimal, and hospital stay was 0.8 days (0.1-1.5). At follow-up, mean $(95 \% \mathrm{CI})$ visual analog scale pain scores improved by 6.1 points (5.7-6.6). Substantial clinical benefit, defined as a decrease in pain by $>2.5$ points or a score of 3.5 or less, was achieved in $91.9 \%$ of patients (95\% CI 83.9\%-96.1\%), and 96\% (95\% CI 86.3\%-98.8\%) of patients indicated they would have the same surgery again.

Conclusion: When conservative measures fail to relieve symptoms resulting from degeneration or disruption of the SI joint, MIS SI joint fusion using a series of triangular, porous, titanium plasma spray-coated implants is a safe and effective treatment option.

Keywords: minimally invasive surgery, sacroiliac joint, SI joint fusion, arthrodesis, previous spine surgery

\section{Introduction}

Chronic low back pain is well known as a public health epidemic. In highly developed countries, it is one of the top three causes of degradation in quality-adjusted life-years, along with ischemic heart disease and chronic obstructive pulmonary disease. ${ }^{1}$ While lumbar spine pathology is an important cause of chronic low back pain, substantial evidence suggests that not all lower-back pain is in fact generated by lumbar spinal structures. The sacroiliac (SI) joint has been found to be a pain generator in up to $30 \%$ of patients diagnosed with lower-back pain. ${ }^{2-5}$ Disorders of the SI joint may be the result of trauma, pregnancy, inflammatory arthritis, osteoarthritis, or degeneration of the joint either de novo or after lumbar spinal fusion. ${ }^{6,7}$ Diagnosing the SI joint as the primary pain generator can be complex, as patients often present with a combination of lower-back, groin, gluteal, and/or leg pain. ${ }^{2,8}$ Furthermore, imaging studies
Correspondence: Robyn Capobianco SI-BONE, Inc., Suite 2200, 3055 Olin Avenue, San Jose, CA 95124 , USA

$\mathrm{Tel}+\mathrm{I} 6502198342$

$\mathrm{Fax}+\mathrm{I} 4085169663$

Email rcapobianco@si-bone.com 
are typically not sensitive to abnormalities in the absence of trauma, ankylosing spondylitis, tumors, or infection.?

SI joint pain can be debilitating and treatment with conservative care is often unsuccessful. The economic burden of conservative care in this population is significant for Medicare, as well as commercial payer entities, at an estimated 3-year cost of US $\$ 1$.6 billion per 100,000 commercial covered lives, and 5 year estimated cost of $\$ 270$ million for Medicare beneficiaries. ${ }^{9,10}$ Furthermore, the impact of pain on persons living with the disease is similar to that associated with other prominent orthopedic conditions routinely treated surgically. ${ }^{11}$

Open arthrodesis of the SI joint was commonly performed throughout the 1900s. ${ }^{12,13}$ However, this technique is less common now, as it requires a relatively large incision, significant bone harvesting, and lengthy hospital stay; moreover, patients must avoid weight-bearing for a prolonged period (up to several months) postoperatively. ${ }^{14} \mathrm{~A}$ recent study comparing open and minimally invasive surgical (MIS) techniques for SI joint fusion demonstrated more favorable outcomes in the MIS cohort with respect to patient-reported outcomes, operative time, hospital stay, and rate of reoperation..$^{15}$

Herein, we report a patient-level meta-analysis of safety and effectiveness outcomes from a multicenter retrospective study of patients treated with MIS SI joint fusion using a series of triangular titanium, porous titanium plasma spraycoated implants (iFuse Implant System ${ }^{\circledR}$; SI-BONE, Inc., San Jose, CA, USA).

\section{Materials and methods}

Consecutive patients who underwent MIS SI joint-fusion surgery at six sites were identified. Patients were included if preoperative and minimum 12-month follow-up data were available. Data extracted from medical charts included demographic information, medical history (including history of prior lumbar spinal fusion), length of hospital stay, surgical operating time, estimated blood loss, complications of surgery, SI joint pain measured on a $0-10$ visual analog scale (VAS), and satisfaction with surgery. Institutional review board approval was obtained at all sites before beginning this study.

\section{Diagnosis}

Pain experienced in the lumbar region can arise from various anatomical structures and pathophysiological functions. ${ }^{16}$ Portions of the sacral plexus from S1 and S2 innervate the SI joint on the dorsal side, and segments from L3 and S2 innervate the ventral side, resulting in possible dermatomal pain patterns anywhere from L2 to $\mathrm{S} 4 .{ }^{17}$ Therefore, differential diagnosis in this complex population is essential. A detailed clinical history coupled with a positive result on three or more physical provocation maneuvers, such as Gaenslen's, flexionabduction-external rotation, compression, distraction, and thigh thrust, were used as criteria for further testing of the SI joint. ${ }^{18}$ Diagnostic imaging studies, such as X-ray, computed tomography (CT) and magnetic resonance imaging (MRI) were performed to assess pathology in the lumbopelvic hip complex. When clinical, physical, and imaging findings were concordant, image-guided diagnostic injections of the SI joint were performed as a final step in diagnosing the SI joint as the primary pain generator. ${ }^{18,19} \mathrm{~A}$ positive result was defined as a $75 \%$ reduction in pain immediately following injection of local anesthetic. All patients in this study failed a 6-month course of nonsurgical treatment consisting of a combination of medication optimization, activity modification, physical therapy, and SI joint injections.

\section{Surgical technique}

Minimally invasive SI joint surgery was performed on all patients using a series of triangular, titanium implants (iFuse Implant System) (Figure 1). The implants are coated with a porous titanium plasma spray, an osteoconductive substrate



Figure I ifuse implants (iFuse Implant System ${ }^{\oplus}$; SI-BONE, Inc., San Jose, CA, USA). 
that has been routinely used in total joint prostheses for decades to accommodate biologic fixation. ${ }^{20} \mathrm{~A}$ radiolucent table was used to facilitate the use of intraoperative fluoroscopy. After general endotracheal anesthesia was administered, the patient was turned prone and prepped in the normal sterile fashion. A lateral incision $(3 \mathrm{~cm})$ was made into the gluteal region, positioned over the first sacral body as viewed on a lateral fluoroscopic image. The fascia was then bluntly dissected to reach the outer table of the ilium. A Steinmann pin was passed through the ilium across the SI joint to the center of the sacrum (lateral to the neural foramen). After a soft-tissue protector was passed over the pin, a hand drill was used to create a pathway through the ilium, across the SI joint, and into the sacrum. Finally, a triangular broach was used to further decorticate the bone and prepare a triangular channel to receive the first implant. Using a pin-guidance system, a total of three implants were placed in the majority of patients. The most cephalad implant was seated within the sacral ala above the first neural foramen. The second implant was located above or adjacent to the $\mathrm{S} 1$ foramen, and the third between the $\mathrm{S} 1$ and $\mathrm{S} 2$ foramen (Figures 2 and 3). The incision was irrigated, and the tissue layers were closed. Postoperatively, patients were instructed to ambulate with partial weight-bearing using the assistance of a walker. A variable program of gradual return to full weight-bearing was employed based on local practices and patient needs.

\section{Statistical analysis}

Baseline demographic variables were summarized, where appropriate, with means, standard deviation, confidence intervals (CIs), and frequency tables. Changes in VAS pain scores were evaluated across sites using mixed models that accounted for each subject's age, sex, history of prior

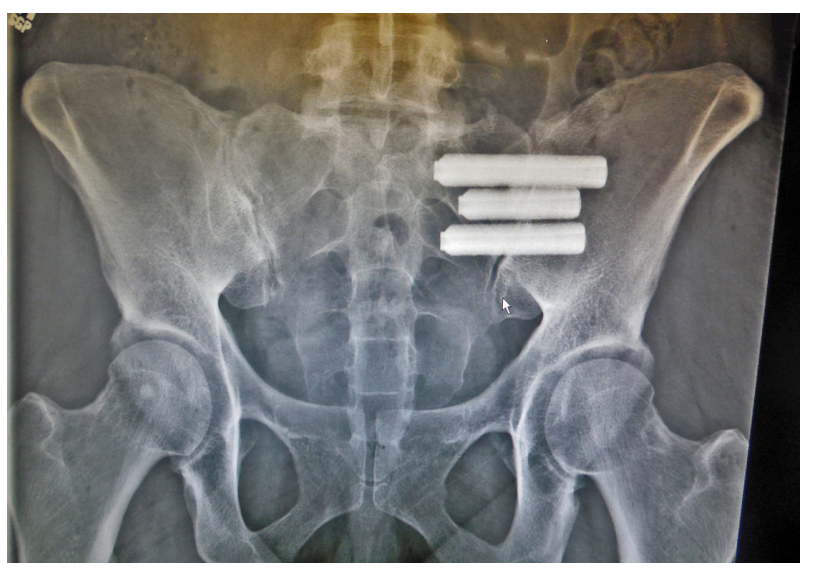

Figure 2 Anteroposterior view of three implants in position.

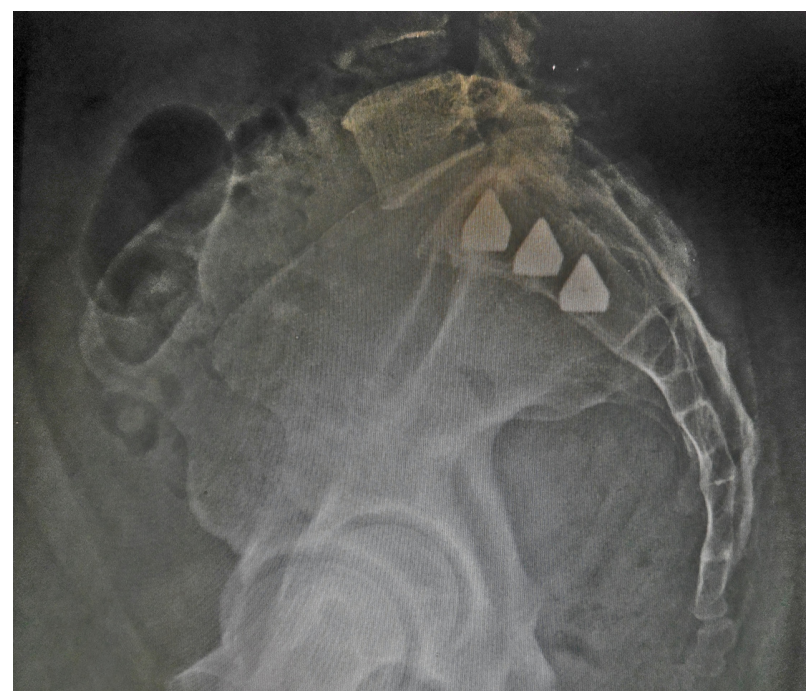

Figure 3 Lateral view of three implants in position.

lumbar fusion, and baseline pain score, and included study site as a random effect. Random-effects models assume that even after controlling for known covariates, outcomes are clustered within sites; models assume that the underlying effect at each site is a random variable rather than a fixed value. Similarly, random-effects logistic regression was used to summarize proportions across sites, controlling for age, sex, and history of prior lumbar fusion. Subgroup analysis was performed similarly, with predefined subgroups: prior lumbar fusion (yes versus no), age greater than or less than 65 years, and sex. When there was significant variation in a baseline characteristic by site, univariate random-effects models taking into account site only were used to report mean values (or proportions) and confidence limits. All analyses were performed using $\mathrm{R}$ software. ${ }^{21}$

Clinical improvement was defined using well-accepted values for minimum clinically important difference (MCID) and substantial clinical benefit (SCB) available in the literature. MCID is defined as a change of $>2.0$ points, and SCB is defined as a 2.5-point decrease or raw score of $<3.5 .^{22,23}$

\section{Results}

The medical charts of 144 subjects were available for review. The mean follow-up time was 16 months (range 12-26) (Table 1$)$. The majority (71\%) of patients at all sites were female, and $62 \%$ of patients had a history of prior lumbar spinal fusion. Mean patient age varied across sites; the randomeffects estimate was 57.7 years (95\% CI 53.0-62.4, range $30-89$ ), and $35 \%$ were over the age of 65 years. The mean baseline pain score was 8.6 (95\% CI 8.1-9.1) (Table 2). At 1 year, patient-reported pain improved clinically and statistically. 
Table I Demographic information

\begin{tabular}{ll}
\hline $\mathbf{n = I 4 4}$ & \\
\hline Age, years, mean & 57.7 (range 30-89, 95\% Cl 53.0-62.4) \\
Sex & $71 \%$ female, 29\% male \\
History of lumbar fusion & $62 \%$ \\
\hline
\end{tabular}

Abbreviation: $\mathrm{Cl}$, confidence interval.

The mean VAS (pain) score dropped to 2.7 (95\% CI 1.8-3.5), representing an improvement of 6.1 points (95\% CI 5.7-6.6). Substantial clinical benefit was achieved in $92 \%$ of patients (95\% CI 84\%-96\%) and MCID was achieved in 90\% (95\% CI $82 \%-95 \%$ ) of patients. When controlling for age, sex, prior lumbar fusion, and study site, the proportion of patients who reported being satisfied or somewhat satisfied at 12 months was $95.7 \%$ (95\% CI 86.3\%-98.8\%). Regression-coefficient modeling performed to assess the effect of age $(>/<65$ years), sex, and history of lumbar spinal fusion, was statistically significant $(t>2)$ for sex only. Mean $(95 \% \mathrm{CI})$ reduction in pain was $-5.9(-6.6$ to -5.2$)$ for men and $-6.2(-6.8$ to -5.6$)$ for women; there were no significant differences for age or history of prior lumbar fusion.

While the majority of patients experienced significant improvement, a small percentage (15 patients, $10 \%$ ), reported a change of 1 point or less on VAS; nine improved by 1 point, and six had no change. Two of these patients were revisions; prior SI joint fusion using percutaneous screws had failed. Both showed improvement on VAS scores from 5 to 4, were satisfied with surgery, and indicated they would have the same surgery again for the same result.

Operating time, available for 42 patients at three sites, averaged 73 minutes (95\% CI 25.4-118) (Table 3). Estimated blood loss, available for all patients, was minimal:

Table 2 Results

\begin{tabular}{ll}
\hline $\mathbf{n = I 4 4}$ & Mean \\
\hline Baseline VAS & $8.6(95 \% \mathrm{Cl} 8 . \mathrm{I}-9 . \mathrm{I})$ \\
I2-month VAS & $2.7(95 \% \mathrm{Cl}$ I.8-3.5) \\
Substantial clinical benefit & $89.8 \%(95 \% \mathrm{Cl} 81.7 \%-94.5 \%)$ \\
Very or somewhat satisfied & $95.7 \%(95 \% \mathrm{Cl} 86.3 \%-98.7 \%)$ \\
Satisfaction with surgery & $\mathbf{n}$ \\
\hline Very satisfied & $\mathrm{III}(77.1 \%)$ \\
Somewhat satisfied & $20(13.9 \%)$ \\
Somewhat unsatisfied & $6(4.2 \%)$ \\
Not satisfied & $7(4.9 \%)$ \\
Would you have the same & $\mathbf{n}$ \\
procedure again? & \\
\hline Yes & $132(91.7 \%)$ \\
No & $\mathrm{II}(7.6 \%)$ \\
Unsure & $\mathrm{I}(0.7 \%)$ \\
\hline
\end{tabular}

Abbreviations: VAS, visual analog scale; $\mathrm{Cl}$, confidence interval.
Table 3 Operative characteristics

\begin{tabular}{ll}
\hline $\begin{array}{l}\text { Side treated } \\
\text { Left }\end{array}$ & $56(39 \%)$ \\
Right & $62(43 \%)$ \\
$\quad$ Bilateral & $26(18 \%)$ \\
OR time, minutes, mean $(n=42)$ & $73(95 \%$ Cl $25.4-1$ I 8$)$ \\
Blood loss, cc, mean $(n=I \mid 6)$ & $31(95 \%$ Cl $25-37)$ \\
Hospital stay, days, mean $(n=109)$ & $0.8(95 \%$ Cl $0.1-1.5)$ \\
\hline
\end{tabular}

Abbreviations: $\mathrm{OR}$, operating room; $\mathrm{Cl}$, confidence interval.

a mean of $31 \mathrm{cc}(95 \%$ CI 25-37). The mean length of hospital stay, available for 109 patients, was 0.8 days $(95 \%$ CI $0.1-1.5)$.

\section{Complications}

No intraoperative complications occurred. A total of 28 postoperative sequelae were reported, the most common were falls (3.5\%), trochanteric bursitis (2.8\%), facet pain (2.1\%), and piriformis syndrome (2.1\%) (Table 4). Two patients returned with contralateral SI joint pain. Both patients reported complete relief of symptoms after undergoing subsequent MIS SI joint fusion on the contralateral side. One patient presented with symptoms of nerve-root impingement, confirmed on CT scan. The patient was returned to the operating room, the original implant was removed and replaced with a shorter implant, and the patient recovered without issue. The revision rate at 1 year was $0.7 \%$.

\section{Discussion}

Intermediate-term ( $>1$ year) follow-up of a large number of patients who underwent MIS SI joint fusion using a series of triangular titanium implants showed high rates of pain relief and satisfaction and low rates of perioperative

Table 4 Adverse events

\begin{tabular}{ll}
\hline Description & $\mathbf{n}$ \\
\hline Fall & 5 \\
Trochanteric bursitis & 4 \\
Piriformis syndrome & 3 \\
Facet pain & 3 \\
Contralateral sacroiliac joint pain & 2 \\
Recurrent pain & 2 \\
Leg pain & $\mathrm{I}$ \\
Numbness in left foot & $\mathrm{I}$ \\
Toe numbness & $\mathrm{I}$ \\
Burning and numbness in upper thigh & $\mathrm{I}$ \\
Bladder incontinence & $\mathrm{I}$ \\
Hematoma & $\mathrm{I}$ \\
Increased pain & $\mathrm{I}$ \\
New lower-back pain & $\mathrm{I}$ \\
Nerve-root impingement requiring reposition of implant & $\mathrm{I}$ \\
Total reported adverse events & 28 \\
\hline
\end{tabular}


or intermediate-term complications. These findings are consistent with prior reports ${ }^{15,24,25}$ and a recently published prospective study. ${ }^{26}$

As with any surgical procedure, an accurate diagnosis is imperative if one is to achieve positive clinical outcomes. Initial clinical presentation in the SI joint patient population can be misleading as several pathophysiologic conditions can present similarly. Structures in the lumbopelvic hip complex are interdependent, and kinematic changes in one area can affect surrounding structures. ${ }^{17}$ A history of sleep disturbance, pain on prolonged sitting, leg instability, and pain in the lower back, buttock, hip, and groin, as well as the SI joint, are common. Furthermore, pain and degeneration of the SI joint after lumbar spinal fusion is common, with up to $43 \%$ of these patients experiencing SI joint pain and $75 \%$ showing radiographic changes. ${ }^{27,28}$ An accurate diagnosis requires a combination of history, physical examination maneuvers that stress the SI joint, and image-guided intraarticular diagnostic injections.

Multiple nonsurgical and surgical treatments for SI joint disorders are available. When nonsurgical management fails to provide adequate relief of symptoms, surgical stabilization is an option. A publication summarizing various arthrodesis techniques (both open and MIS) reports variable improvements in pain and function, with more invasive approaches reporting moderately high complications and nonunions. ${ }^{15}$ Overall, MIS techniques have a record of significant improvements in pain and function, but results vary with implant and patient selection.

Similar to other reports, the majority of patients in the present cohort had a history of previous lumbar spinal fusion. It is unclear whether the degradation of the SI joint in these patients was a result of adjacent segment disease or de novo degeneration. However, in contrast to other technique reports, ${ }^{29}$ clinical outcomes using the triangular implants used herein were not diminished in this patient population.

Favorable outcomes in patients with prior lumbar spinal fusion underscore the necessity to suspect the SI joint as a pain generator in patients with lower-back pain. The low success rate of spinal fusion combined with the high incidence of SI joint disorders discovered in patients presenting with lowerback pain leads one to suspect whether the SI joint is being overlooked as a pain generator in these patients. ${ }^{3}$ Lower-back pain can obscure SI joint disorders, and current imaging technology may not be sensitive in detecting inciting pathology.

The type and number of postsurgical adverse events in our study was commensurate with other published studies using this device system. ${ }^{15,24-26}$ The most commonly reported complications in the cohort reported herein were trochanteric bursitis and piriformis syndrome. These events are neither uncommon nor unexpected, and can be a result of altered gait pattern due to lower-back or hip pain, postoperative hip-abductor weakness, increased activity levels, and other trauma in the region. Miller et al conducted an analysis of complaints (adverse events) reported to the device manufacturer (SI-BONE, Inc.) as part of an ongoing postmarket surveillance program. ${ }^{30}$ They reported a complication rate of $3.8 \%$ in 5,319 patients, and events included pain due to nerve impingement, hematoma at the operative site, iliac fracture, wound infection, device migration, and implant malposition. Revision surgery was reported in $1.8 \%$ of patients.

The current study has limitations. This retrospective chart review lacked patient-reported outcomes, such as the Oswestry Disability Index and Short Form (SF-36) Health Survey, available in controlled trials. Radiological outcomes were not assessed; bony bridging cannot be reliably assessed on plain-film radiographs. ${ }^{6}$ Furthermore, in the absence of symptoms requiring further imaging, the cost and radiation exposure of CT scanning precludes such imaging studies from being performed routinely.

The study also has strengths. It was a large multicenter study with intermediate-term (greater than 1 year) outcomes. The patient-level meta-analysis provided a method of examining outcomes that accounted for differences in patient characteristics across sites, subsequently providing more accurate results.

\section{Conclusion}

For patients with SI joint pain recalcitrant to conservative treatment, minimally invasive surgical fusion of the SI joint using a series of triangular porous titanium plasma spray-coated implants is a safe surgical option that provides significant symptom relief with a high degree of patient satisfaction.

\section{Disclosure}

This study was sponsored by SI-BONE, Inc. No funds were received by the authors in support of this work. DS, JC, MG, $\mathrm{TH}, \mathrm{TG}$, and ANS receive teaching honoraria from SI-BONE, Inc. RC and DC are SI-BONE, Inc. employees.

\section{References}

1. Vos T, Flaxman AD, Naghavi M, et al. Years lived with disability (YLDs) for 1160 sequelae of 289 diseases and injuries 1990-2010: a systematic analysis for the Global Burden of Disease Study 2010. Lancet. 2012;380(9859):2163-2196.

2. Schwarzer AC, Aprill CN, Bogduk N. The sacroiliac joint in chronic low back pain. Spine (Phila Pa 1976). 1995;20(1):31-37. 
3. Sembrano JN, Polly DW. How often is low back pain not coming from the back? Spine (Phila Pa 1976). 2009;34(1):E27-E32.

4. Maigne JY, Aivaliklis A, Pfefer F. Results of sacroiliac joint double block and value of sacroiliac pain provocation tests in 54 patients with low back pain. Spine (Phila Pa 1976). 1996;21(16):1889-1892.

5. Bernard TN, Kirkaldy-Willis WH. Recognizing specific characteristics of nonspecific low back pain. Clin Orthop Relat Res. 1987;(217):266-280.

6. Dar G, Peleg S, Masharawi Y, et al. Sacroiliac joint bridging: demographical and anatomical aspects. Spine (Phila Pa 1976). 2005;30(15):E429-E432.

7. Broadhurst NA, Bond MJ. Pain provocation tests for the assessment of sacroiliac joint dysfunction. J Spinal Disord. 1998;11(4):341-345.

8. Foley BS, Buschbacher RM. Sacroiliac joint pain: anatomy, biomechanics, diagnosis, and treatment. Am J Phys Med Rehabil. 2006;85(12): 997-1006.

9. Ackerman S, Cummings J, Polly D, Knight T, Schneider K, Holt T. Comparison of the costs of nonoperative care to minimally invasive surgery for sacroiliac joint disruption and degenerative sacroiliitis in a United States Medicare population: potential economic implications of a new minimally-invasive technology. Clinicoecon Outcomes Res. 2013;2013(5):575-587.

10. Ackerman SJ, Polly DW Jr, Knight T, Holt T, Cummings J Jr. Nonoperative care to manage sacroiliac joint disruption and degenerative sacroiliitis: high costs and medical resource utilization in the United States Medicare population. J Neurosurg Spine. 2014;20(4):354-363.

11. Cher D, Polly D, Berven S. Sacroiliac joint pain: burden of disease. Med Devices (Auckl). 2014;7:73-81.

12. Moore MR. Surgical treatment of chronic painful sacroiliac joint dysfunction. In: Vleeming A, Mooney V, Snijders CJ, Dorman TA, Stoeckart R, editors. Movement, Stability, and Low Back Pain: The Essential Role of the Pelvis. New York: Churchill Livingstone; 1997: 563-572.

13. Waisbrod H, Krainick JU, Gerbershagen HU. Sacroiliac joint arthrodesis for chronic lower back pain. Arch Orthop Trauma Surg. 1987;106(4):238-240.

14. Lorio MP, Polly DW Jr, Ninkovic I, Ledonio CG, Hallas K, Andersson G. Utilization of minimally invasive surgical approach for sacroiliac joint fusion in surgeon population of ISASS and SMISS membership. Open Orthop J. 2014;8:1-6.

15. Smith AG, Capobianco R, Cher D, et al. Open versus minimally invasive sacroiliac joint fusion: a multi-center comparison of perioperative measures and clinical outcomes. Ann Surg Innov Res. 2013;7(1):14.

16. Sizer PS Jr, Phelps V, Matthijs O. Pain generators of the lumbar spine. Pain Pract. 2001;1(3):255-273.
17. Sizer PS, Phelps V, Thompsen K. Disorders of the sacroiliac joint. Pain Pract. 2002;2(1):17-34.

18. Szadek KM, van der Wurff P, van Tulder MW, Zuurmond WW, Perez RS. Diagnostic validity of criteria for sacroiliac joint pain: a systematic review. J Pain. 2009;10(4):354-368.

19. Laslett M. Evidence-based diagnosis and treatment of the painful sacroiliac joint. J Man Manip Ther. 2008;16(3):142-152.

20. Mallory TH, Head WC, Lombardi AV Jr, Emerson RH Jr, Eberle RW, Mitchell MB. Clinical and radiographic outcome of a cementless, titanium, plasma spray-coated total hip arthroplasty femoral component. Justification for continuance of use. J Arthroplasty. 1996;11(6): 653-660.

21. R Project [website on the Internet]. Available from: http://www.rproject.org. Accessed July 18, 2014.

22. Copay AG, Glassman SD, Subach BR, Berven S, SchulerTC, Carreon LY. Minimum clinically important difference in lumbar spine surgery patients: a choice of methods using the Oswestry Disability Index, Medical Outcomes Study questionnaire Short Form 36, and pain scales. Spine J. 2008;8(6):968-974.

23. Glassman SD, Copay AG, Berven SH, Polly DW, Subach BR, Carreon LY. Defining substantial clinical benefit following lumbar spine arthrodesis. J Bone Joint Surg. 2008;90(9):1839-1847.

24. Rudolf L. Sacroiliac joint arthrodesis-MIS technique with titanium implants: report of the first 50 patients and outcomes. Open Orthop J. 2012;6(1):495-502.

25. Sachs D, Capobianco R. Minimally invasive sacroiliac joint fusion: one-year outcomes in 40 patients. Adv Orthop. 2013;2013:536128.

26. Duhon B, Cher D, Wine K, Lockstadt H, Kovalsky D, Soo CL. Safety and 6-month effectiveness of minimally invasive sacroiliac joint fusion: a prospective study. Med Devices (Auckl). 2013;6:219-229.

27. Slinkard N, Agel J, Swiontkowski MF. Documentation of outcomes for sacroiliac joint fusion: does prior spinal fusion influence the outcome? Eur Spine J. 2013;22(10):2318-2324.

28. Liliang PC, Lu K, Liang CL, Tsai YD, Wang KW, Chen HJ. Sacroiliac joint pain after lumbar and lumbosacral fusion: findings using dual sacroiliac joint blocks. Pain Med. 2011;12(4):565-570.

29. Mason LW, Chopra I, Mohanty K. The percutaneous stabilisation of the sacroiliac joint with hollow modular anchorage screws: a prospective outcome study. Eur Spine J. 2013;22(10):2325-2331.

30. Miller L, Reckling WC, Block JE. Analysis of postmarket complaints database for the iFuse SI Joint Fusion System: a minimally invasive treatment for degenerative sacroiliitis and sacroiliac joint disruption. Med Devices (Auckl). 2013;6:77-84.
Medical Devices: Evidence and Research

\section{Publish your work in this journal}

Medical Devices: Evidence and Research is an international, peerreviewed, open access journal that focuses on the evidence, technology, research, and expert opinion supporting the use and application of medical devices in the diagnosis, treatment and management of clinical conditions and physiological processes. The identification of novel

\section{Dovepress}

devices and optimal use of existing devices which will lead to improved clinical outcomes and more effective patient management and safety is a key feature. The manuscript management system is completely online and includes a quick and fair peer-review system. Visit http://www. dovepress.com/testimonials.php to read real quotes from authors. 